\title{
Diagnostic Accuracy of Cerebrospinal Fluid Amyloid- $\beta$ Isoforms for Early and Differential Dementia Diagnosis
}

\author{
Hanne Struyfs ${ }^{\mathrm{a}, 1}$, Bianca Van Broeck ${ }^{\mathrm{b}, 1}$, Maarten Timmers ${ }^{\mathrm{c}}$, Erik Fransen ${ }^{\mathrm{d}}$, Kristel Sleegers ${ }^{\mathrm{e}, \mathrm{f}}$, \\ Christine Van Broeckhoven ${ }^{\mathrm{e}, \mathrm{f}}$, Peter P. De Deyn ${ }^{\mathrm{a}, \mathrm{g}, \mathrm{h}}$, Johannes R. Streffer ${ }^{\mathrm{c}}$, Marc Mercken ${ }^{\mathrm{b}}$ \\ and Sebastiaan Engelborghs ${ }^{\mathrm{a}, \mathrm{g}, *}$ \\ ${ }^{a}$ Reference Center for Biological Markers of Dementia (BIODEM), and Biobank, Institute Born-Bunge, University \\ of Antwerp, Antwerp, Belgium \\ b Janssen Research and Development, Neuroscience Discovery, Beerse, Belgium \\ ${ }^{\mathrm{c} J a n s s e n ~ R e s e a r c h ~ a n d ~ D e v e l o p m e n t, ~ E x p e r i m e n t a l ~ M e d i c i n e ~ N e u r o s c i e n c e, ~ B e e r s e, ~ B e l g i u m ~}$ \\ ${ }^{\mathrm{d}}$ StatUa Center for Statistics, University of Antwerp, Antwerp, Belgium \\ e Neurodegenerative Brain Diseases Group, Department of Molecular Genetics, VIB, Antwerp, Belgium \\ ${ }^{\mathrm{f}}$ Laboratory of Neurogenetics, Institute Born-Bunge, University of Antwerp, Antwerp, Belgium \\ $\mathrm{g}$ Department of Neurology and Memory Clinic, Hospital Network Antwerp (ZNA) Middelheim and Hoge Beuken, \\ Antwerp, Belgium \\ ${ }^{\mathrm{h}}$ Department of Neurology and Alzheimer Research Center, University of Groningen and University Medical Center \\ Groningen (UMCG), Groningen, The Netherlands
}

Handling Associate Editor: Piotr Lewczuk

Accepted 29 December 2014

\begin{abstract}
.
Background: Overlapping cerebrospinal fluid biomarkers (CSF) levels between Alzheimer's disease (AD) and non-AD patients decrease differential diagnostic accuracy of the AD core CSF biomarkers. Amyloid- $\beta$ (A $\beta$ ) isoforms might improve the AD versus non-AD differential diagnosis.

Objective: To determine the added diagnostic value of $A \beta$ isoforms, $A \beta_{1-37}, A \beta_{1-38}$, and $A \beta_{1-40}$, as compared to the AD CSF biomarkers $A \beta_{1-42}$, T-tau, and P-tau $181 \mathrm{P}$.

Methods: CSF from patients with dementia due to $\mathrm{AD}(n=50)$, non-AD dementias $(n=50)$, mild cognitive impairment due to $\mathrm{AD}(n=50)$ and non-demented controls $(n=50)$ was analyzed with a prototype multiplex assay using MSD detection technology. The non-AD group consisted of frontotemporal dementia (FTD; $n=17$ ), dementia with Lewy bodies (DLB; $n=17$ ), and vascular dementia $(n=16)$.

Results: $A \beta_{1-37}$ and $A \beta_{1-38}$ increased accuracy to differentiate AD from FTD or DLB. $A \beta_{1-37}, A \beta_{1-38}$, and $A \beta_{1-40}$ levels correlated with Mini-Mental State Examination scores and disease duration in dementia due to $A D$. The $A \beta_{1-42} / A \beta_{1-40}$ ratio improved diagnostic performance of $A \beta_{1-42}$ in most differential diagnostic situations. $A \beta_{1-42}$ levels were lower in $A P O E \varepsilon 4$ carriers compared to non-carriers.
\end{abstract}

\footnotetext{
${ }^{1}$ These authors contributed equally to this work.

*Correspondence to: Prof. Dr. Sebastiaan Engelborghs, University of Antwerp, Reference Center for Biological Markers
}

of Dementia (BIODEM), Universiteitsplein 1, 2610 Antwerp, Belgium. Tel.: +32 326523 94; Fax: +32 326526 18; E-mail: Sebastiaan.Engelborghs@uantwerpen.be. 
Conclusions: $A \beta$ isoforms help to differentiate AD from FTD and DLB. A $\beta$ isoforms increase diagnostic performance of $A \beta_{1-42}$. In contrast to $A \beta_{1-42}$, $A \beta$ isoforms seem to be correlated with disease severity in $A D$. Adding the $A \beta$ isoforms to the current biomarker panel could enhance diagnostic accuracy.

Keywords: Alzheimer's disease, amyloid, biological markers, cerebrospinal fluid, diagnosis, differential, mild cognitive impairment

\section{INTRODUCTION}

Amyloid plaques, one of the major neuropathological hallmarks of Alzheimer's disease (AD), mainly consist of aggregates of carboxyterminally elongated forms of amyloid- $\beta(A \beta)$ peptides [1], resulting from cleavage of the transmembrane amyloid- $\beta$ protein precursor by $\beta$ - and $\gamma$-secretases [2]. The most abundant $A \beta$ peptides in cerebrospinal fluid (CSF) are $A \beta_{1-38}$, $A \beta_{1-40}$, and $A \beta_{1-42}$ [3], of which $A \beta_{1-42}$ is the most pathological in $\mathrm{AD}$ as it is most prone to aggregation into $A \beta$ plaques [4].

The combined assessment of CSF $A \beta_{1-42}$, total tau protein (T-tau), and tau phosphorylated at threonine 181 (P-tau $181 \mathrm{P})$ increases diagnostic certainty for AD [5]. Compared to controls, the AD CSF biomarker profile consists of decreased $A \beta_{1-42}$ and increased $T$ tau and/or P-tau $181 \mathrm{P}$ concentrations. However, when compared to non-AD dementias, these differences are less pronounced as the concentrations in patients with non-AD dementias are generally intermediate between those found in controls and AD patients, indicating an overlap between AD and non-AD patients [6].

Determining CSF A $\beta$ isoforms might improve the $\mathrm{AD}$ versus non-AD differential diagnosis, as some evidence exists that $A \beta_{1-42} / A \beta_{1-40}$ or $A \beta_{1-42} / A \beta_{1-38}$ ratios improve discriminating $\mathrm{AD}$ from non- $\mathrm{AD}$ dementias in comparison to $\mathrm{A} \beta_{1-42}$ alone [7, 8]. Indeed, several studies have shown the CSF levels of $A \beta_{1-38}$ are decreased in frontotemporal dementia (FTD) as compared to AD and non-demented controls $[9,10]$. Using the $A \beta_{1-42} / A \beta_{1-38}$ ratio, FTD could be differentiated from $\mathrm{AD}$ with a sensitivity and specificity of $82 \%$ [9]. As AD pathology is common in dementia with Lewy bodies (DLB) and the presence of senile plaques in DLB patients is associated with low CSF $A \beta_{1-42}$ concentrations, the determination of CSF $A \beta_{1-42}$ levels is of limited value for discriminating $\mathrm{AD}$ and $\mathrm{DLB}$ [11]. However, it has been shown that the ratios of $A \beta_{1-42} / A \beta_{1-37}$ and $A \beta_{1-42} / A \beta_{1-38}$ can differentiate between AD and DLB $[12,13]$.

In this study, the $A \beta$ isoforms $A \beta_{1-37}, A \beta_{1-38}$, $A \beta_{1-40}$, and $A \beta_{1-42}$ were analyzed and four research questions were explored: 1) Do $A \beta$ isoforms correlate with disease severity in $\mathrm{AD}$ ?; 2) Do the
$\mathrm{A} \beta$ isoforms levels differ between apolipoprotein $\mathrm{E}$ $(A P O E) \varepsilon 4$ carriers and non-carriers?; 3 ) Does the ratio of $A \beta_{1-42} / A \beta_{1-40}$ increase the diagnostic performance of $A \beta_{1-42}$ alone?; 4) What is the added diagnostic value of the $A \beta$ isoforms?

The potential diagnostic accuracy of the $A \beta$ peptides, $A \beta_{1-37}, A \beta_{1-38}, A \beta_{1-40}$, and $A \beta_{1-42}$, was assessed for differential dementia diagnoses as well as for early $\mathrm{AD}$ diagnosis. In addition, in order to evaluate the added value of the $A \beta$ isoforms, their diagnostic values were compared to the diagnostic values of $\mathrm{A} \beta_{1-42}$, T-tau, and P-tau $181 \mathrm{P}$.

\section{METHODS}

\section{Study population}

Samples from patients and controls were selected from the Biobank of the Institute Born-Bunge. Only samples from patients recruited in the Memory Clinic and Department of Neurology of Hospital Network Antwerp (ZNA) were selected to avoid inter-center variability due to possible differences in pre-analytical steps. Patients with dementia due to $\mathrm{AD}(n=50)$, mild cognitive impairment (MCI) due to $\mathrm{AD}(n=50)$, and patients with non-AD dementias $(n=50)$ were included. The non-AD group consisted of 17 patients with FTD, 17 DLB patients, and 16 patients with vascular dementia (VaD).

Patients with MCI and dementia due to AD were diagnosed according to the NIA-AA criteria [14, 15], with at least intermediate probability of AD etiology (based on the CSF biomarkers or hippocampal volume on MRI). MCI due to AD and dementia due to AD will hereafter be referred to as 'MCI' and 'AD', respectively. FTD, DLB, and VaD were diagnosed according to the criteria described by Neary et al. [16], the clinical diagnostic criteria of McKeith et al. [17], and the NINDS-AIREN criteria [18], respectively.

The control group consisted of cognitively healthy elderly $(n=35)$ in whom cognitive deterioration was ruled out by means of neuropsychological screening. Cognitively healthy elderly also fulfilled the following inclusion criteria: 1) no neurological or psychiatric antecedents and 2) no central nervous system disease 
following extensive clinical examination. The control group also consisted of patients with neurological diseases in whom neurodegenerative disorders were ruled out by means of an extensive neurological work-up $(n=15)$. The study was approved by the local ethics committee (University Hospital Antwerp) and all subjects gave their written informed consent.

\section{CSF sampling}

Lumbar puncture (LP), CSF sampling and handling have been performed according to a standard protocol [19]. CSF samples were stored at $-80^{\circ} \mathrm{C}$ until analysis.

\section{CSF biomarker analyses}

CSF biomarker analyses of $\mathrm{A} \beta_{1-42}, \mathrm{~T}$-tau, and $\mathrm{P}$-tau $\mathrm{t}_{181 \mathrm{P}}$ were performed using commercially available single parameter ELISA kits (INNOTEST ${ }^{\circledR}$, Fujirebio Europe, Ghent, Belgium) at the BIODEM lab as previously described [20]. CSF biomarker analyses of $A \beta_{1-37}, A \beta_{1-38}$, and $A \beta_{1-40}$ were performed at QPS Netherlands BV (Groningen, The Netherlands) with a prototype multiplex assay developed by Janssen Research and Development that uses Meso Scale Discovery (MSD) detection technology as previously described [21].

Briefly, the multiplex assay involved a sandwich immunoassay with electrochemoluminescence detection. Standards of human $A \beta_{1-37}, A \beta_{1-38}$, and $A \beta_{1-40}$ (AnaSpec, San Jose, USA) were dissolved in dimethylsulphoxide at $0.1 \mathrm{mg} / \mathrm{mL}$ and stored at $-80^{\circ} \mathrm{C}$. For use in the assay, peptides were further diluted in casein buffer $(0.1 \%$ casein in PBS). Purified monoclonal antibodies specific for $A \beta_{1-37}$ (JRD/A $\left.\beta 37 / 3\right), A \beta_{1-38}$ (J\&JPRD/A $\beta 38 / 5)$, and $A \beta_{1-40}(\mathrm{JRF} / \mathrm{cA} \beta 40 / 28)$ were coated on MSD 4-plex 96-well plates on spatially distinct spots. Plates were blocked with casein buffer for $1-4 \mathrm{~h}$ at room temperature. After washing, standards, quality control samples, and $1 / 2$ prediluted CSF samples were incubated overnight at $4{ }^{\circ} \mathrm{C}$ together with MSD SULFO-TAG ${ }^{\mathrm{TM}}$-labeled human-specific detection antibody JRF/A $\beta N / 25$. JRF/A $\beta N / 25$ detects an end-specific epitope of $A \beta$ leading to the detection of full-length $A \beta$ peptides $\left(A \beta_{1-x}\right)$. After overnight incubation, plates were washed, after which $2 x$ Read Buffer (MSD) was added according to the manufacturer's recommendations and plates were read on MSD Sector Imager 6000. $A \beta_{1-37}, A \beta_{1-38}$, and $A \beta_{1-40}$ concentrations were determined by interpolation from the standard curve using MSD Workbench software and 4 parameter logistic model with $1 / \mathrm{Y}^{2}$ weighting function. All calibration standards and CSF samples were analyzed in duplicate. Only mean values with a replicate well coefficient of variation $(\mathrm{CV})$ of less than or equal to $20.0 \%$ were accepted. The samples of the different diagnostic groups were tested randomized over multiple plates. The means for the interplate $\mathrm{CV}$ for the quality control samples were less than $12 \%$ for all analytes. The upper and lower limit of quantification, determined as the highest and lowest calibrator concentration for which overall $\mathrm{CV}$ and bias were $\leq 25.0 \%$, was $4.57 \mathrm{pg} / \mathrm{mL}$ and $10000 \mathrm{pg} / \mathrm{mL}$, respectively, for all measured $A \beta$ peptides.

\section{Disease severity in $A D$}

Disease severity of AD was estimated by MiniMental State Examination (MMSE) scores and disease duration. MMSE tests were always performed 3 months before or after LP. If available, the yearly change in MMSE, i.e., the difference between the earliest MMSE score and the most recent one divided by their time interval, was also reported. Disease duration was considered as the difference between age at onset and age at LP.

\section{APOE genotyping}

The isolation of genomic DNA from peripheral blood lymphocytes was performed at the Genetic Service Facility (http://www.vibgeneticservicefacility.be) of the VIB Department of Molecular Genetics on a Magtration ${ }^{\circledR}$ System 8Lx. robotic platform. SNPs in $A P O E$ (rs429358 and rs7412, determining the $\varepsilon 2 / \varepsilon 3 / \varepsilon 4$ polymorphism) were genotyped by Sanger sequencing.

\section{Statistical analyses}

Statistical analyses were performed using SPSS 20. First, a Kolmogorov-Smirnov test was performed to check for normal distribution. Since most variables did not follow a normal distribution, non-parametric tests were used. To compare gender distribution and $A P O E$ carrier status across the groups a Chi-square test was performed. A Kruskal-Wallis test was used to compare biomarker data over all groups. Subsequently, Mann-Whitney U tests were performed to compare groups separately. To assess correlations, Spearman's Rho correlation tests were performed. Receiver operating characteristic (ROC) curve analyses were used to obtain area under the curve (AUC) values and to define optimal cut-off values to discriminate $\mathrm{MCI}$ and $\mathrm{AD}$ 


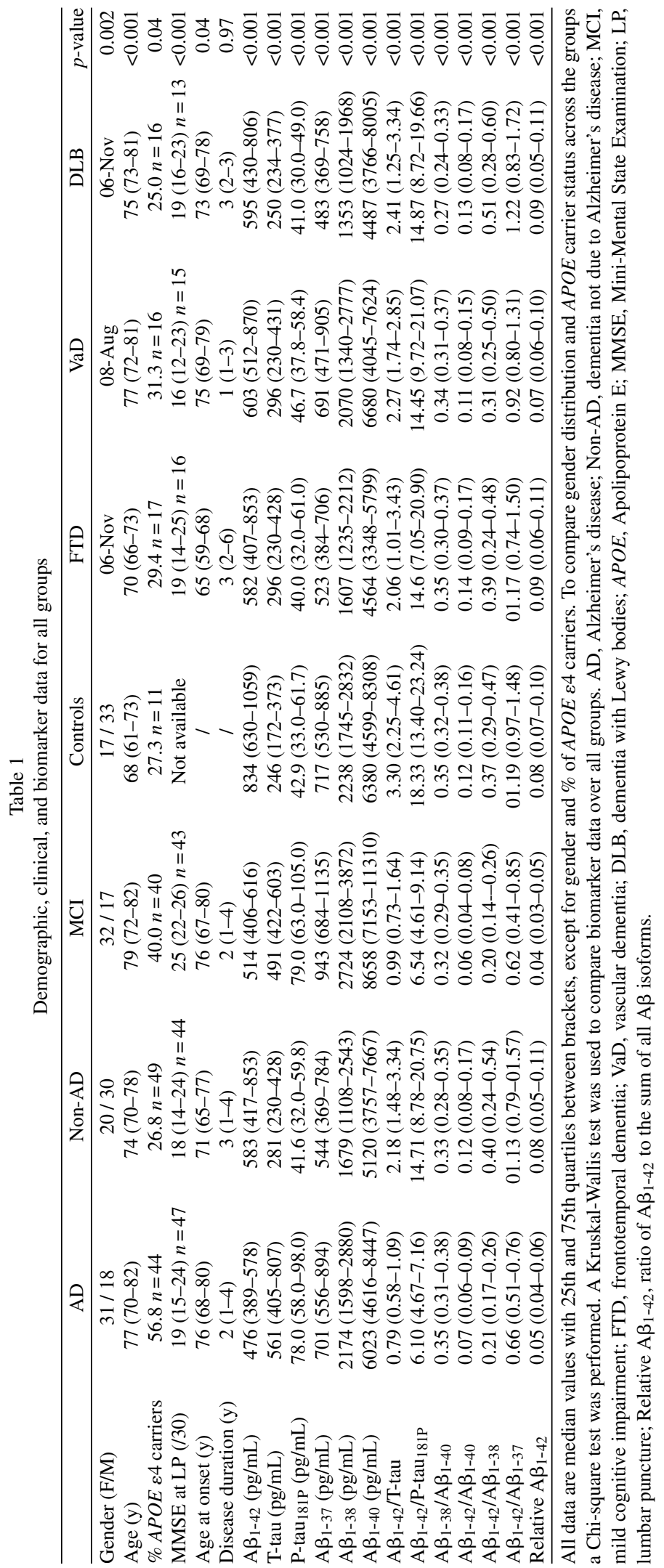


from all other groups. The cut-off values were determined by calculating the maximal sum of sensitivity and specificity (i.e., maximizing the Youden index). In order to compare AUC values, DeLong tests were performed by using the pROC package [22] in the statistical software package $\mathrm{R}$ (R Core Team). Correction for multiple testing was not performed due to the small study population and the explorative nature of this study.

\section{RESULTS}

Study population: Demographic, clinical, and biomarker data

One AD patient and one MCI patient were excluded from statistical analyses because of all their $A \beta$ isoforms concentrations being below the lowest range. The groups were not age- and gender-matched. Table 1 summarizes demographic, clinical, and biomarker data for all groups.

\section{Correlation with MMSE}

In the MCI group, none of the correlations were significant (Table 2). However, in the AD group, $A \beta_{1-37}$, $\mathrm{A} \beta_{1-38}$, and $\mathrm{A} \beta_{1-40}$ correlated moderately with MMSE scores. Yearly change in MMSE correlated significantly but weakly $(p<0.05)$ with $\mathrm{A} \beta_{1-42}$ in the MCI group.

\section{Correlation with disease duration}

In the $\mathrm{AD}$ population, the correlations of $\mathrm{A} \beta_{1-38}$, $A \beta_{1-40}$, and $A \beta_{1-42} / A \beta_{1-40}$ with disease duration were weak but significant (Table 2 ).

\section{Effect of $A P O E \varepsilon 4$}

The $A \beta$ isoforms levels were compared between subjects carrying one or two $\varepsilon 4$ alleles $(n=58)$ and noncarriers $(n=86)$ (Table 3$)$. A $\beta_{1-42}$ was significantly lower in $\varepsilon 4$ carriers $(p<0.001)$, while $A \beta_{1-37}, A \beta_{1-38}$, and $A \beta_{1-40}$ were not significantly different.

In the MCI and AD populations separately none of the biomarkers differed significantly between $\varepsilon 4$ carriers and non-carriers. However, when combining both diagnostic groups, $A \beta_{1-42}$ was significantly lower in carriers than non-carriers $(p<0.05)$. This was also found in the non-AD group $(p<0.05)$.

\section{Diagnostic accuracy}

The ROC curve analysis results of the best performing biomarkers are summarized in Table 4, while the remaining data are given in the Supplementary Material.

\section{$A D$ versus $M C I$}

$\mathrm{A} \beta_{1-42}$, T-tau, and P-tau $181 \mathrm{P}$ did not differentiate between MCI and AD, keeping in mind these analytes were used to define these groups. The AUC values of the $A \beta$ isoforms were below 0.800 (Supplementary Table 1).

\section{$A D$ and MCI versus controls}

The biomarkers performing best when comparing $\mathrm{AD}$ patients and controls were $\mathrm{A} \beta_{1-42} / \mathrm{T}$-tau and $A \beta_{1-42} / \mathrm{P}-\operatorname{tau}_{181 \mathrm{P}} . A \beta_{1-42} / \mathrm{A} \beta_{1-40}$ performed comparably to $A \beta_{1-42}$ for discriminating $A D$ from controls (Table 5; Supplementary Table 2).

The biomarkers performing best when comparing MCI patients and controls were $A \beta_{1-42} / \mathrm{T}$-tau and $A \beta_{1-42} / A \beta_{1-40} . A \beta_{1-42} / A \beta_{1-40}$ as well as $A \beta_{1-42} / A \beta_{1-37}$ significantly increased the performance of $A \beta_{1-42}$ alone to discriminate MCI and controls (Table 5; Supplementary Table 2).

\section{$A D$ and $M C I$ versus non- $A D$}

The best performing biomarkers when comparing $\mathrm{AD}$ patients and non-AD dementias were the $\mathrm{A} \beta_{1-42} / \mathrm{T}$ tau and $A \beta_{1-42} / \mathrm{P}-\operatorname{tau}_{181 \mathrm{P}}$ ratios. The $\mathrm{AUC}$ values of the $A \beta_{1-42} / A \beta_{1-38}$ and $A \beta_{1-42} / A \beta_{1-37}$ ratios reached the 0.800 threshold and were significantly higher than the AUC of $A \beta_{1-42}$ alone (Table 5; Supplementary Table 3 ).

When comparing MCI with non-AD dementia patients, the best performing biomarkers were $\mathrm{P}$ $\operatorname{tau}_{181 \mathrm{P}}$ and $\mathrm{A} \beta_{1-42} / \mathrm{A} \beta_{1-40} . \quad \mathrm{A} \beta_{1-42} / \mathrm{A} \beta_{1-38}$ and $A \beta_{1-42} / A \beta_{1-37}$ also significantly increased the power of $A \beta_{1-42}$ to discriminate between MCI and non-AD (Table 5; Supplementary Table 3).

\section{$A D$ and MCI versus FTD}

The best biomarkers to distinguish $\mathrm{AD}$ and FTD were $A \beta_{1-42} / A \beta_{1-37}$ and the relative value of $A \beta_{1-42}$, i.e., the ratio of $A \beta_{1-42}$ to the sum of all $A \beta$ isoforms (Supplementary Table 4). All ratios increased the performance of $A \beta_{1-42}$ significantly (Table 5). 
Table 2

Correlation of the levels of the A $\beta$ isoforms with MMSE scores, yearly MMSE score change and disease duration in the MCI and AD populations

\begin{tabular}{|c|c|c|c|c|c|}
\hline & $\mathrm{A} \beta_{1-37}$ & $\mathrm{~A} \beta_{1-38}$ & $\mathrm{~A} \beta_{1-40}$ & $\mathrm{~A} \beta_{1-42}$ & $\mathrm{~A} \beta_{1-42} / \mathrm{A} \beta_{1-40}$ \\
\hline \multicolumn{6}{|c|}{ Correlation with MMSE scores } \\
\hline \multicolumn{6}{|c|}{ MCI population } \\
\hline Correlation Coefficient & 0.207 & 0.150 & 0.248 & 0.066 & -0.047 \\
\hline$p$-value & 0.182 & 0.338 & 0.109 & 0.672 & 0.765 \\
\hline$n$ & 43 & 43 & 43 & 43 & 43 \\
\hline \multicolumn{6}{|l|}{ AD population } \\
\hline Correlation Coefficient & 0.520 & 0.431 & 0.450 & 0.264 & -0.214 \\
\hline$p$-value & 0.000 & 0.003 & 0.002 & 0.073 & 0.148 \\
\hline$n$ & 47 & 47 & 47 & 47 & 47 \\
\hline \multicolumn{6}{|c|}{ Correlation with yearly change in MMSE scores } \\
\hline \multicolumn{6}{|c|}{ MCI population } \\
\hline Correlation Coefficient & 0.239 & 0.231 & 0.099 & 0.362 & 0.187 \\
\hline$p$-value & 0.148 & 0.162 & 0.554 & 0.026 & 0.261 \\
\hline$n$ & 38 & 38 & 38 & 38 & 38 \\
\hline \multicolumn{6}{|l|}{ AD population } \\
\hline Correlation Coefficient & -0.135 & -0.158 & -0.047 & -0.197 & -0.106 \\
\hline$p$-value & 0.405 & 0.330 & 0.772 & 0.223 & 0.514 \\
\hline$n$ & 40 & 40 & 40 & 40 & 40 \\
\hline \multicolumn{6}{|c|}{ Correlation with disease duration } \\
\hline \multicolumn{6}{|c|}{ MCI population } \\
\hline Correlation Coefficient & -0.063 & 0.031 & 0.013 & 0.032 & -0.023 \\
\hline$p$-value & 0.670 & 0.832 & 0.930 & 0.827 & 0.878 \\
\hline$n$ & 49 & 49 & 49 & 49 & 49 \\
\hline \multicolumn{6}{|l|}{ AD population } \\
\hline Correlation Coefficient & 0.255 & 0.370 & 0.388 & 0.034 & -0.397 \\
\hline$p$-value & 0.077 & 0.009 & 0.006 & 0.816 & 0.005 \\
\hline$n$ & 49 & 49 & 49 & 49 & 49 \\
\hline
\end{tabular}

Median change in MMSE over time in the AD group was $-1.2(-3.8-(-0.3))$ over a median time interval of 2.7 years (1.3-4.5). In the MCI population, the median MMSE change was -3.6 (-1.8-(-0.5)) over a median time interval of 3.6 years (2.4-5.8). AD, Alzheimer's disease; MCI, mild cognitive impairment; MMSE, Mini-Mental State Examination.

Table 3

Comparison of the $\mathrm{A} \beta$ isoforms between $A P O E \varepsilon 4$ carriers and non-carriers

\begin{tabular}{|c|c|c|c|c|c|}
\hline & $n$ & $\mathrm{~A} \beta_{1-37}(\mathrm{pg} / \mathrm{mL})$ & $\mathrm{A} \beta_{1-38}(\mathrm{pg} / \mathrm{mL})$ & $\mathrm{A} \beta_{1-40}(\mathrm{pg} / \mathrm{mL})$ & $\mathrm{A} \beta_{1-42}(\mathrm{pg} / \mathrm{mL})$ \\
\hline \multicolumn{6}{|l|}{ All groups } \\
\hline Non-carrier & 86 & $691(497-894)$ & $2,111(1,456-2,804)$ & $6,669(4,426-8,585)$ & $578(433-824)$ \\
\hline Carrier & 58 & $707(556-943)$ & $2,186(1,607-2,831)$ & $6,251(5,018-8,664)$ & $469(378-548)$ \\
\hline$p$-value & & 0.273 & 0.489 & 0.824 & 0.000 \\
\hline \multicolumn{6}{|c|}{ AD population } \\
\hline Non-carrier & 19 & $593(518-882)$ & $1,934(1,488-2,575)$ & $5,497(4,329-7,230)$ & $500(417-600)$ \\
\hline Carrier & 25 & $701(591-888)$ & $2,018(1,797-2,631)$ & $5,928(5,018-7,580)$ & $443(321-508)$ \\
\hline$p$-value & & 0.118 & 0.678 & 0.337 & 0.110 \\
\hline \multicolumn{6}{|c|}{ MCI population } \\
\hline Non-carrier & 24 & $865(648-1,081)$ & $2,661(2,069-3,410)$ & $8,650(7,004-11,292)$ & $520(421-621)$ \\
\hline Carrier & 16 & $951(698-1,119)$ & $2,756(2,268-3,605)$ & $8,553(7,671-10,104)$ & $495(330-577)$ \\
\hline$p$-value & & 0.629 & 0.679 & 0.679 & 0.263 \\
\hline \multicolumn{6}{|c|}{ Combination $M C I$ and $A D$} \\
\hline Non-carrier & 43 & $742(536-980)$ & $2,427(1,644-3,267)$ & $7,230(5,326-9,535)$ & $513(417-606)$ \\
\hline Carrier & 41 & $727(637-971)$ & $2,300(1,856-2,880)$ & $6,843(5,403-8,956)$ & $462(321-541)$ \\
\hline$p$-value & & 0.579 & 0.961 & 0.690 & 0.040 \\
\hline \multicolumn{6}{|c|}{ Non-AD population } \\
\hline Non-carrier & 35 & $562(414-768)$ & $1,679(1,108-2,576)$ & $5,388(3,821-7,667)$ & 714 (509-915) \\
\hline Carrier & 14 & $558(369-866)$ & $1,715(1,225-2,543)$ & $5,120(3,348-8,005)$ & $502(397-584)$ \\
\hline$p$-value & & 0.982 & 0.965 & 0.912 & 0.026 \\
\hline
\end{tabular}

All data are median values with 25 th and 75 th quartiles between brackets, except for N. AD, Alzheimer's disease; Non-AD, dementia not due to Alzheimer's disease; MCI, mild cognitive impairment. 
Table 4

Best performing biomarkers for all differential diagnostic situations based on ROC curve analyses

\begin{tabular}{|c|c|c|c|c|c|c|c|c|c|}
\hline & \multicolumn{4}{|c|}{$\mathrm{AD}$ versus controls } & & \multicolumn{4}{|c|}{ MCI versus controls } \\
\hline & AUC & cut-off & sens [\%] & spec $[\%]$ & & AUC & cut-off & sens [\%] & spec $[\%]$ \\
\hline $\mathrm{A} \beta_{1-42} / \mathrm{T}-\mathrm{tau}$ & 0.968 & $<1.708$ & 93.9 & 92.0 & $\mathrm{~A} \beta_{1-42} / \mathrm{T}-\mathrm{tau}$ & 0.922 & $<1.861$ & 83.7 & 90.0 \\
\hline \multirow[t]{2}{*}{$\mathrm{A} \beta_{1-42} / \mathrm{P}-\operatorname{tau}_{181 \mathrm{P}}$} & 0.930 & $<10.122$ & 91.8 & 86.0 & $\mathrm{~A} \beta_{1-42} / \mathrm{A} \beta_{1-40}$ & 0.924 & $<0.1024$ & 91.8 & 84.0 \\
\hline & \multicolumn{4}{|c|}{$\mathrm{AD}$ versus non-AD } & & \multicolumn{4}{|c|}{ MCI versus non-AD } \\
\hline $\mathrm{A} \beta_{1-42} / \mathrm{T}-\mathrm{tau}$ & 0.842 & $<1.420$ & 87.8 & 76.0 & P-tau $181 P$ & 0.857 & $>57.50 \mathrm{pg} / \mathrm{mL}$ & 89.8 & 74.0 \\
\hline \multirow{2}{*}{$\mathrm{A} \beta_{1-42} / \mathrm{P}-\operatorname{tau}_{181 \mathrm{P}}$} & 0.840 & $<9.440$ & 87.8 & 72.0 & $\mathrm{~A} \beta_{1-42} / \mathrm{A} \beta_{1-40}$ & 0.845 & $<0.1022$ & 91.8 & 62.0 \\
\hline & \multicolumn{4}{|c|}{ AD versus FTD } & & \multicolumn{4}{|c|}{ MCI versus FTD } \\
\hline Relative $A \beta_{1-42}$ & 0.831 & $<0.0768$ & 91.8 & 58.8 & Relative $A \beta_{1-42}$ & 0.875 & $<0.0491$ & 67.3 & 94.1 \\
\hline \multirow[t]{2}{*}{$\mathrm{A} \beta_{1-42} / \mathrm{A} \beta_{1-37}$} & 0.851 & $<0.7351$ & 69.4 & 94.1 & $\mathrm{~A} \beta_{1-42} / \mathrm{A} \beta_{1-40}$ & 0.882 & $<0.0944$ & 85.7 & 75.0 \\
\hline & \multicolumn{4}{|c|}{$\mathrm{AD}$ versus $\mathrm{VaD}$} & & \multicolumn{4}{|c|}{ MCI versus $\mathrm{VaD}$} \\
\hline $\mathrm{A} \beta_{1-42} / \mathrm{T}-\mathrm{tau}$ & 0.902 & $<1.589$ & 89.8 & 87.5 & P-tau $181 P$ & 0.881 & $>59.90 \mathrm{pg} / \mathrm{mL}$ & 85.7 & 81.3 \\
\hline \multirow[t]{2}{*}{$\mathrm{A} \beta_{1-42} / \mathrm{P}-\operatorname{tau}_{181 \mathrm{P}}$} & 0.912 & $<8.096$ & 79.6 & 93.8 & $\mathrm{~A} \beta_{1-42} / \mathrm{P}-\operatorname{tau}_{181 \mathrm{P}}$ & 0.860 & $<8.092$ & 67.3 & 93.8 \\
\hline & \multicolumn{4}{|c|}{ AD versus DLB } & & \multicolumn{4}{|c|}{ MCI versus DLB } \\
\hline $\mathrm{A} \beta_{1-42} / \mathrm{A} \beta_{1-38}$ & 0.843 & $<0.3957$ & 95.9 & 70.6 & P-tau $181 P$ & 0.855 & $>49.50 \mathrm{pg} / \mathrm{mL}$ & 95.9 & 76.5 \\
\hline $\mathrm{A} \beta_{1-42} / \mathrm{T}-\mathrm{tau}$ & 0.838 & $<1.222$ & 83.7 & 76.5 & $\mathrm{~A} \beta_{1-38}$ & 0.855 & $>1850.00 \mathrm{pg} / \mathrm{mL}$ & 87.8 & 70.6 \\
\hline
\end{tabular}

$\mathrm{AD}$, Alzheimer's disease; MCI, mild cognitive impairment; AUC, area under the curve; sens, sensitivity; spec, specificity.

Table 5

Significance levels ( $p$-values) of the AUC value comparisons of the A $\beta$ isoforms ratios with $A \beta_{1-42}$ alone

\begin{tabular}{|c|c|c|c|}
\hline $\begin{array}{l}\text { Differential } \\
\text { diagnosis }\end{array}$ & $\mathrm{A} \beta_{1-42} / \mathrm{A} \beta_{1-40}$ & $\mathrm{~A} \beta_{1-42} / \mathrm{A} \beta_{1-38}$ & $\mathrm{~A} \beta_{1-42} / \mathrm{A} \beta_{1-37}$ \\
\hline AD versus controls & 0.857 & 0.688 & 0.918 \\
\hline MCI versus controls & 0.002 & 0.102 & 0.049 \\
\hline $\mathrm{AD}$ versus non-AD & 0.113 & 0.049 & 0.016 \\
\hline MCI versus non-AD & 0.000 & 0.000 & 0.000 \\
\hline AD versus FTD & 0.025 & 0.039 & 0.008 \\
\hline MCI versus FTD & 0.000 & 0.002 & 0.001 \\
\hline $\mathrm{AD}$ versus $\mathrm{VaD}$ & 0.979 & 0.899 & 0.899 \\
\hline MCI versus $\mathrm{VaD}$ & 0.034 & 0.133 & 0.103 \\
\hline AD versus DLB & 0.392 & 0.058 & 0.061 \\
\hline MCI versus DLB & 0.009 & 0.002 & 0.002 \\
\hline
\end{tabular}

DeLong tests were performed by using the pROC package in the statistical software package R to compare the AUC values. AUC, area under the curve; AD, Alzheimer's disease; Non-AD, dementia not due to Alzheimer's disease; MCI, mild cognitive impairment; FTD, frontotemporal dementia; VaD, vascular dementia; DLB, dementia with Lewy bodies.

The $A \beta_{1-42} / A \beta_{1-40}$ ratio was the best biomarker to distinguish MCI and FTD. $A \beta_{1-40}, A \beta_{1-42} / A \beta_{1-38}$, and $A \beta_{1-42} / A \beta_{1-37}$ also performed well, with all ratios significantly increasing the performance of $A \beta_{1-42}$ (Table 5; Supplementary Table 4).

\section{$A D$ and MCI versus VaD}

The best biomarkers to distinguish $\mathrm{AD}$ and $\mathrm{VaD}$ were $A \beta_{1-42} /$ T-tau and $A \beta_{1-42} / \mathrm{P}-\operatorname{tau}_{181 \mathrm{P}}$, comparable to the $\mathrm{AD}$ versus controls situation. The diagnostic accuracy of $A \beta_{1-42}$ was not increased by ratios with the other $A \beta$ isoforms (Table 5; Supplementary Table 5).

The best performing biomarker when differentiating $\mathrm{MCI}$ and $\mathrm{VaD}$ was P-tau $181 \mathrm{P}$. The $\mathrm{A} \beta_{1-42} / \mathrm{A} \beta_{1-40}$ ratio increased the diagnostic accuracy of $\mathrm{A} \beta_{1-42}$ significantly (Table 5; Supplementary Table 5).

\section{$A D$ and $M C I$ versus $D L B$}

The best biomarkers to differentiate between $\mathrm{AD}$ and DLB were $A \beta_{1-42} / A \beta_{1-38}$ and $A \beta_{1-42} /$ T-tau (Supplementary Table 6). Similar performances were found for T-tau, $A \beta_{1-42} / A \beta_{1-37}, \mathrm{P}-\operatorname{tau}_{181 \mathrm{P}}$, and $A \beta_{1-38} / A \beta_{1-40}$. The diagnostic accuracy of $A \beta_{1-42}$ was not increased by any isoform ratio (Table 5).

The best performing biomarkers to differentiate MCI and DLB were P-tau $181 \mathrm{P}$ and $A \beta_{1-38}$. The $A \beta_{1-42} / A \beta_{1-38}$ ratio and $A \beta_{1-37}$ performed similarly. The performance of $A \beta_{1-42}$ was substantially increased by the ratios with the other $A \beta$ isoforms (Table 5; Supplementary Table 6). 


\section{DISCUSSION}

This study was set up to investigate the potential diagnostic value of the $A \beta$ peptides, $A \beta_{1-37}, A \beta_{1-38}$, and $A \beta_{1-40}$, for differential dementia diagnosis as well as for early $\mathrm{AD}$ diagnosis. In addition, in order to evaluate the added value of the $A \beta$ isoforms, their diagnostic values were compared to the diagnostic values of $\mathrm{A} \beta_{1-42}$, T-tau, and P-tau $181 \mathrm{P}$.

The four research questions posed in this study will be further discussed in this section. The research questions regarding diagnostic performance of $A \beta_{1-42} / A \beta_{1-40}$ and with regard to the added value of the $A \beta$ isoforms are combined in the subsection 'Diagnostic performance' as they largely coincide.

\section{Correlation with disease severity in $A D$}

When assessing the correlation of the $A \beta$ isoforms as well as the $A \beta_{1-42} / A \beta_{1-40}$ ratio with MMSE scores and disease duration, significant weak to moderate correlations were found in the $\mathrm{AD}$ population, except for the $A \beta_{1-42} / A \beta_{1-40}$ ratio. On the other hand, no significant correlations in the MCI population were found. Similar results were found by Mulugeta et al. [13], though they had to combine all investigated patients in order to find significant correlations. Our results imply there might be a correlation of the $A \beta$ isoforms with disease severity in $\mathrm{AD}$ and the $\mathrm{A} \beta$ isoforms could have a prognostic value in $\mathrm{AD}$. However, this needs further investigation in larger, independent cohorts before any conclusions can be drawn.

\section{Difference between APOE \&4 carriers and non-carriers}

The $A \beta$ isoforms, $A \beta_{1-37}, A \beta_{1-38}$, and $A \beta_{1-40}$, were not different between $\varepsilon 4$ carriers and non-carriers. The levels of $A \beta_{1-42}$ were always lower in $\varepsilon 4$ carriers as compared to non-carriers, although this difference was not always significant. In the AD and MCI groups separately, none of the biomarkers were significantly different between carriers and non-carriers. However, when combining both $\mathrm{AD}$ and $\mathrm{MCI}$ groups, there was a significant difference in the level of $A \beta_{1-42}$ between carriers and non-carriers, which could be a confirmation of results found in a study on autopsy-confirmed AD patients [23]. This change in significance could be caused by the higher power when combining both groups. In the pooled non-AD population a significant difference was found in levels of $A \beta_{1-42}$. This difference might be explained by the fact that $\varepsilon 4$ is a risk factor for $\mathrm{AD}$ co-pathology in the brain of non-AD dementias as well [11].

\section{Diagnostic performance}

$\mathrm{A} \beta_{1-42}$, T-tau, and P-tau $181 \mathrm{P}$ did not differentiate between MCI and AD. This was to be expected, since both groups have $\mathrm{AD}$ and these biomarkers have almost reached their maximal increase or decrease in MCI, only changing minimally with disease evolution as from the MCI stage. Interestingly, comparable differences were found regarding the $\mathrm{A} \beta$ isoforms when comparing MCI and $\mathrm{AD}$ with controls and the non-AD groups. This once more points to the common AD pathophysiology in MCI and $\mathrm{AD}$ groups. Based on the ROC analyses, the $\mathrm{A} \beta$ isoforms were able to differentiate between MCI and AD groups, although the AUC values were below 0.800 . This might be explained by the moderate correlation of the $A \beta$ isoforms with disease severity. Both results might point to changes of these isoforms with $\mathrm{AD}$ progression, in contrast to $A \beta_{1-42}$ that remains stable.

When comparing MCI and AD and controls, analyzing $A \beta$ isoforms has an added value, as $A \beta_{1-42} / A \beta_{1-40}$ performed slightly better as compared to $A \beta_{1-42}$ for discriminating $\mathrm{AD}$ from controls and substantially better fordiscriminating MCI and controls. However, since the AUC value of $A \beta_{1-42} / A \beta_{1-40}$ is comparable or lower than those of $A \beta_{1-42} / T$-tau and $A \beta_{1-42} / \mathrm{P}-\operatorname{tau}_{181 \mathrm{P}}$, the added diagnostic value of the $A \beta$ isoforms is considered to be limited.

According to our in-house validated $A \beta_{1-42}$ cut-off to discriminate $\mathrm{AD}$ from cognitively healthy elderly $(638.5 \mathrm{pg} / \mathrm{mL})$, five patients had normal $A \beta_{1-42}$ levels. However, their $A \beta_{1-42} / A \beta_{1-40}$ ratio was decreased as compared to controls, although this difference was not significant $(p>0.05)$, probably due to the small number of patients. We hypothesize that the $A \beta_{1-42} / A \beta_{1-40}$ ratio has a diagnostic value in AD patients having normal values of $A \beta_{1-42}$, since the $A \beta_{1-42} / A \beta_{1-40}$ ratio is decreased in these patients as compared to controls $[24,25]$, which should be further investigated in larger cohorts.

Given our results for AD versus FTD, analyzing $\mathrm{A} \beta_{1-37}$ has an added diagnostic value. It should also be noted our results for $A \beta_{1-38}$ are comparable to those of Gabelle et al. [10]. However, in contrast to Gabelle et al. [10], we found no added value of $A \beta_{1-38}$ for the differential diagnosis of AD and FTD given the relatively low AUC (not exceeding 0.800). In addition, we found similar sensitivity but lower specificity values for $A \beta_{1-42} / A \beta_{1-38}$ as Bibl et al. [9] for discriminating $\mathrm{AD}$ and FTD. 
To differentiate $\mathrm{AD}$ and $\mathrm{VaD}$, the core $\mathrm{AD}$ biomarkers performed best. The $A \beta_{1-42} / A \beta_{1-40}$ ratio increased the diagnostic accuracy of $A \beta_{1-42}$ alone, pointing to a diagnostic value of the $A \beta$ isoforms. However, since the AUC values were not higher than those of $\mathrm{A} \beta_{1-42} / \mathrm{T}$-tau and $A \beta_{1-42} / \mathrm{P}-\operatorname{tau}_{181 \mathrm{P}}$ in the $\mathrm{AD}$ versus $\mathrm{VaD}$ situation and $\mathrm{P}-\operatorname{tau}_{181 \mathrm{P}}$ and $\mathrm{A} \beta_{1-42} / \mathrm{P}-\operatorname{tau}_{181 \mathrm{P}}$ in the MCI versus $\mathrm{VaD}$ situation, the added diagnostic value is limited.

As the AUC value of $A \beta_{1-42} / A \beta_{1-38}$ when comparing $\mathrm{AD}$ and DLB was only a little higher than the AUC value of $A \beta_{1-42} / T-$ tau, the added diagnostic value of $A \beta_{1-38}$ is only limited. This also held true for MCI and DLB, as the best performing biomarkers $\mathrm{P}-\operatorname{tau}_{181 \mathrm{P}}$ and $A \beta_{1-38}$ had equal AUC values. The performance of $A \beta_{1-42} / A \beta_{1-38}$ confirmed earlier findings $[12,13]$. Although these previous studies pointed to a disease specific peptide pattern, our study shows that the added diagnostic value of such a pattern is questionable.

Regarding the pooled non-AD group, the $\mathrm{A} \beta$ isoforms had no added diagnostic value, which is probably due to the fact this group is a combination of three pathophysiologically different disorders and the $A \beta$ isoforms might behave differently in these different neurodegenerative disorders. Although the ratios of $A \beta_{1-42}$ increased the discriminative power of $A \beta_{1-42}$, analyzing $\mathrm{A} \beta$ isoforms did not have an added value for differentiating $\mathrm{MCI}$ or $\mathrm{AD}$ from pooled non-AD dementias as the routine biomarkers still performed better.

In summary, the diagnostic performance of $A \beta_{1-42}$ increased when calculating the $A \beta_{1-42} / A \beta_{1-40}$ ratio. This was the case when comparing the AD groups with FTD and when comparing MCI with non-AD in general, but also FTD, DLB, and VaD separately and controls. Furthermore it was shown there is an added diagnostic value of the $A \beta$ isoforms for differentiating $\mathrm{AD}$ and FTD. The added diagnostic value was only limited when comparing the AD groups with $\mathrm{VaD}, \mathrm{DLB}$, and controls. Rather, altered $A \beta_{1-42} / A \beta_{1-40}$ ratios in CSF might be specific for AD since both peptides are representative for the two possible cleavage routes of the protease $\gamma$-secretase [26].

The present findings should be replicated and confirmed in a larger and independent cohort of patients, including autopsy-confirmed cases.

\section{CONCLUSION}

In conclusion, the $A \beta$ isoforms could help in some differential diagnostic situations. Adding the A $\beta$ isoforms to the current biomarker panel could enhance diagnostic accuracy. This is the case for discriminating AD from FTD and MCI from all other diagnoses and to diagnose $A D$ in patients with normal $A \beta_{1-42}$ levels. In contrast to $A \beta_{1-42}, A \beta$ isoforms seem to be correlated with disease severity in AD.

\section{ACKNOWLEDGMENTS}

This work was supported by an unrestricted research grant from Janssen Pharmaceutica NV, Belgium; by the University of Antwerp Research Fund; the Alzheimer Research Foundation (SAO-FRA); the central Biobank facility of the Institute BornBunge/University Antwerp; the Research Foundation Flanders (FWO); the Agency for Innovation by Science and Technology (IWT); the Belgian Science Policy Office Interuniversity Attraction Poles (IAP) program; the Flemish Government initiated Methusalem excellence grant; and the University of Antwerp Research Fund, Belgium. This work is part of the BIOMARKAPD project within the EU Joint Programme for Neurodegenerative Disease Research (JPND). This work has received support from the EU/EFPIA Innovative Medicines Initiative Joint Undertaking (EMIF grant $\mathrm{n}^{\circ}$ 115372).

The authors acknowledge the assistance of Mrs. Jill Luyckx (Institute Born-Bunge, Antwerp, Belgium) as well as the administrative assistance and the clinical staff of the Department of Neurology and Memory Clinic of Hospital Network Antwerp (ZNA), Middelheim and Hoge Beuken, Antwerp, Belgium.

Authors' disclosures available online (http://j-alz. com/manuscript-disclosures/14-1986r2).

\section{SUPPLEMENTARY MATERIAL}

The supplementary material is available in the electronic version of this article: http://dx.doi.org/ 10.3233/JAD-141986.

\section{REFERENCES}

[1] Glenner GG, Wong CW (1984) Alzheimer's disease: Initial report of the purification and characterization of a novel cerebrovascular amyloid protein. Biochem Biophys Res Commun 120, 885-890.

[2] Haass C, Selkoe DJ (1993) Cellular processing of betaamyloid precursor protein and the genesis of amyloid beta-peptide. Cell 75, 1039-1042.

[3] Wiltfang J, Esselmann H, Bibl M, Smirnov A, Otto M, Paul S, Schmidt B, Klafki HW, Maler M, Dyrks T, Bienert M, Beyermann M, Ruther E, Kornhuber J (2002) Highly conserved and disease-specific patterns of carboxyterminally truncated Abeta peptides 1-37/38/39 in addition to 1-40/42 
in Alzheimer's disease and in patients with chronic neuroinflammation. J Neurochem 81, 481-496.

[4] Blennow K, de Leon MJ, Zetterberg H (2006) Alzheimer's disease. Lancet 368, 387-403.

[5] Blennow K, Hampel H, Weiner M, Zetterberg H (2010) Cerebrospinal fluid and plasma biomarkers in Alzheimer disease. Nat Rev Neurol 6, 131-144.

[6] Engelborghs S, Le Bastard N (2012) The impact of cerebrospinal fluid biomarkers on the diagnosis of Alzheimer's disease. Mol Diagn Ther 16, 135-141.

[7] Welge V, Fiege O, Lewczuk P, Mollenhauer B, Esselmann H, Klafki HW, Wolf S, Trenkwalder C, Otto M, Kornhuber J, Wiltfang J, Bibl M (2009) Combined CSF tau, p-tau181 and amyloid-beta 38/40/42 for diagnosing Alzheimer's disease. $J$ Neural Transm 116, 203-212.

[8] Spies PE, Slats D, Sjogren JM, Kremer BP, Verhey FR, Rikkert MG, Verbeek MM (2010) The cerebrospinal fluid amyloid beta42/40 ratio in the differentiation of Alzheimer's disease from non-Alzheimer's dementia. Curr Alzheimer Res 7, 470-476.

[9] Bibl M, Gallus M, Welge V, Esselmann H, Wolf S, Ruther E, Wiltfang J (2012) Cerebrospinal fluid amyloid-beta 2-42 is decreased in Alzheimer's, but not in frontotemporal dementia. J Neural Transm 119, 805-813.

[10] Gabelle A, Roche S, Geny C, Bennys K, Labauge P, Tholance Y, Quadrio I, Tiers L, Gor B, Boulanghien J, Chaulet C, Vighetto A, Croisile B, Krolak-Salmon P, Perret-Liaudet A, Touchon J, Lehmann S (2011) Decreased sA $\beta P P \beta, A \beta 38$, and A $\beta 40$ cerebrospinal fluid levels in frontotemporal dementia. J Alzheimers Dis 26, 553-563.

[11] Slaets S, Le Bastard N, Theuns J, Sleegers K, Verstraeten A, De Leenheir E, Luyckx J, Martin JJ, Van Broeckhoven C, Engelborghs S (2013) Amyloid pathology influences abeta142 cerebrospinal fluid levels in dementia with lewy bodies. $J$ Alzheimers Dis 35, 137-146.

[12] Bibl M, Mollenhauer B, Esselmann H, Lewczuk P, Trenkwalder C, Brechlin P, Ruther E, Kornhuber J, Otto M, Wiltfang J (2006) CSF diagnosis of Alzheimer's disease and dementia with Lewy bodies. J Neural Transm 113, 1771-1778.

[13] Mulugeta E, Londos E, Ballard C, Alves G, Zetterberg H, Blennow K, Skogseth R, Minthon L, Aarsland D (2011) CSF amyloid beta38 as a novel diagnostic marker for dementia with Lewy bodies. J Neurol Neurosurg Psychiatry 82, 160-164.

[14] Albert MS, DeKosky ST, Dickson D, Dubois B, Feldman HH, Fox NC, Gamst A, Holtzman DM, Jagust WJ, Petersen RC, Snyder PJ, Carrillo MC, Thies B, Phelps CH (2011) The diagnosis of mild cognitive impairment due to Alzheimer's disease: Recommendations from the National Institute on Aging-Alzheimer's Association workgroups on diagnostic guidelines for Alzheimer's disease. Alzheimers Dement 7, 270-279.

[15] McKhann GM, Knopman DS, Chertkow H, Hyman BT, Jack CR Jr, Kawas CH, Klunk WE, Koroshetz WJ, Manly JJ, Mayeux R, Mohs RC, Morris JC, Rossor MN, Scheltens P, Carrillo MC, Thies B, Weintraub S, Phelps $\mathrm{CH}$ (2011) The diagnosis of dementia due to Alzheimer's disease: Recommendations from the National Institute on Aging-Alzheimer's Association workgroups on diagnostic guidelines for Alzheimer's disease. Alzheimers Dement 7, 263-269.
[16] Neary D, Snowden JS, Gustafson L, Passant U, Stuss D, Black S, Freedman M, Kertesz A, Robert PH, Albert M, Boone K, Miller BL, Cummings J, Benson DF (1998) Frontotemporal lobar degeneration: A consensus on clinical diagnostic criteria. Neurology 51, 1546-1554.

[17] McKeith IG, Galasko D, Kosaka K, Perry EK, Dickson DW, Hansen LA, Salmon DP, Lowe J, Mirra SS, Byrne EJ, Lennox G, Quinn NP, Edwardson JA, Ince PG, Bergeron C, Burns A, Miller BL, Lovestone S, Collerton D, Jansen EN, Ballard C, de Vos RA, Wilcock GK, Jellinger KA, Perry RH (1996) Consensus guidelines for the clinical and pathologic diagnosis of dementia with Lewy bodies (DLB): Report of the consortium on DLB international workshop. Neurology 47, 1113-1124.

[18] Roman GC, Tatemichi TK, Erkinjuntti T, Cummings JL, Masdeu JC, Garcia JH, Amaducci L, Orgogozo JM, Brun A, Hofman A (1993) Vascular dementia: Diagnostic criteria for research studies. Report of the NINDS-AIREN International Workshop. Neurology 43, 250-260.

[19] Engelborghs S, De Vreese K, Van de Casteele T, Vanderstichele H, Van Everbroeck B, Cras P, Martin JJ, Vanmechelen E, De Deyn PP (2008) Diagnostic performance of a CSFbiomarker panel in autopsy-confirmed dementia. Neurobiol Aging 29, 1143-1159.

[20] Le Bastard N, Aerts L, Sleegers K, Martin JJ, Van Broeckhoven C, De Deyn PP, Engelborghs S (2013) Longitudinal stability of cerebrospinal fluid biomarker levels: Fulfilled requirement for pharmacodynamic markers in Alzheimer's disease. J Alzheimers Dis 33, 807-822.

[21] Van Broeck B, Borgers M, Meulders G, Hermans B, Dhuyvetter D, Borghys H, Mercken M (2013) Simultaneous evaluation of Abeta37/38/40/42 levels after treatment with secretase inhibitors and modulators using a novel immunoassay. Neurodegener Dis 11

[22] Robin X, Turck N, Hainard A, Tiberti N, Lisacek F, Sanchez JC, Muller M (2011) pROC: An open-source package for $\mathrm{R}$ and $\mathrm{S}+$ to analyze and compare ROC curves. BMC Bioinformatic 12, 77.

[23] Tapiola T, Pirttila T, Mehta PD, Alafuzofff I, Lehtovirta M, Soininen H (2000) Relationship between apoE genotype and CSF beta-amyloid (1-42) and tau in patients with probable and definite Alzheimer's disease. Neurobiol Aging 21, 735-740.

[24] Slaets S, Le Bastard N, Martin JJ, Sleegers K, Van Broeckhoven C, De Deyn PP, Engelborghs S (2013) Cerebrospinal fluid Abeta1-40 improves differential dementia diagnosis in patients with intermediate P-tau181P levels. J Alzheimers Dis 36, 759-767.

[25] Lewczuk P, Zimmermann R, Wiltfang J, Kornhuber J (2009) Neurochemical dementia diagnostics: A simple algorithm for interpretation of the CSF biomarkers. J Neural Transm 116, 1163-1167.

[26] Kakuda N, Shoji M, Arai H, Furukawa K, Ikeuchi T, Akazawa K, Takami M, Hatsuta H, Murayama S, Hashimoto Y, Miyajima M, Arai H, Nagashima Y, Yamaguchi H, Kuwano R, Nagaike K, Ihara Y, Japanese Alzheimer's Disease Neuroimaging I (2012) Altered gamma-secretase activity in mild cognitive impairment and Alzheimer's disease. EMBO Mol Med 4, 344-352. 